\title{
Influence mechanism of miRNA-144 on proliferation and apoptosis of osteosarcoma cells
}

\author{
XU ZHANG, ZHENGWEI LI, WEI JI, XILONG CHEN, QIANG GAO, DAJIN LI and HAIHUI QIN \\ Department of Trauma Neurosurgery, Xuzhou Children's Hospital, \\ Xuzhou Medical University, Xuzhou, Jiangsu 221006, P.R. China
}

Received October 4, 2019; Accepted December 2, 2019

DOI: $10.3892 /$ ol.2019.11197

\begin{abstract}
Influence mechanism of miRNA-144 on proliferation and apoptosis of osteosarcoma cells was investigated. A total of 51 cases of osteosarcoma tissue samples were collected in the department of orthopedic surgery, Xuzhou Children's Hospital, Xuzhou Medical University from January 2014 to February 2017. Additionally, 48 cases of normal bone tissues were collected. qRT-PCR was used to detect the expression of miR-144. Correlation of miR-144 expression in serum and cancer tissues was detected. ROC curve was drawn to analyze the diagnostic value of miR-144 in patients with osteosarcoma. CCK-8 was used to detect the effect of miR-144 on the proliferation ability of U2-OS after transfection. The ratio of U2-OS apoptosis after miR-144 transfection was detected by flow cytometry. Western blot analysis was used to detect the expression of Bax, caspase-3 and $\mathrm{Bcl}-2$ proteins in U2-OS after transfection. The relative expression of miR-144 in osteosarcoma and osteosarcoma serum was significantly lower than that in normal bone tissue and normal human serum $(\mathrm{P}<0.05)$. Serum in patients was positively correlated with the expression of miR-144 in cancer tissues. The area under the miR-144 curve was 0.852 , 95\% CI, 0.768-0.936. The relative expression of miR-144 in MG-63 and U2-OS cells was significantly lower than that in hFOB1.19 cells $(\mathrm{P}<0.05)$, while significantly lower in U2-OS cells than in MG-63 cells $(\mathrm{P}<0.05)$. Proliferation ability of U2-OS cells transfected with miR-144-mimics was significantly inhibited and the apoptosis rate was significantly increased $(\mathrm{P}<0.05)$. Bcl-2 protein was significantly decreased by detection of WB and the expression of Bax and caspase- 3 protein was significantly increased $(\mathrm{P}<0.05)$. miR-144 may be involved in the occurrence and deterioration of osteosarcoma.
\end{abstract}

Correspondence to: Dr Haihui Qin, Department of Trauma Neurosurgery, Xuzhou Children's Hospital, Xuzhou Medical University, 18 Sudi North Road, Xuzhou, Jiangsu 221006, P.R. China E-mail: q3g65m@163.com

Key words: miR-144, osteosarcoma, proliferation, apoptosis, U2-OS
miR-144 can regulate proliferation and apoptosis of U2-OS cells. It is expected to become a new diagnostic and index target for osteosarcoma.

\section{Introduction}

Osteosarcoma is a very common malignant tumor in orthopedics and often occurs in children. Surgery is the most common method for the treatment of osteosarcoma (1). Amputation is mainly to achieve therapeutic purposes, which is one of the main reasons for the poor life quality of patients with osteosarcoma (2). Therefore, early diagnosis and conservative treatment of osteosarcoma is particularly important for the clinic. At present, researchers world-wide are striving to explore the possible serum markers in osteosarcoma (3-5), but still have not made a significant breakthrough. Studies have pointed out that the median survival time of patients with advanced osteosarcoma is only $\sim 20$ months (6). Therefore, in-depth understanding of osteosarcoma and the search for potential diagnostic targets are currently under intense investigations $(7,8)$.

With the deepening of research, increasing number of studies have pointed out that the occurrence of osteosarcoma may be related to microRNAs (miRNAs) $(9,10)$, which are widely distributed in tissues and cells. They play an important role in a series of biological activities such as cell proliferation, apoptosis, metabolism and differentiation (11). As a non-coding single-stranded tiny molecule RNA, miRNA is composed of 21-25 nucleotides. Through the combination of incomplete complementary sequences with the 3 ' untranslated region (3'UTR) sequence of target mRNA (12), miRNA can inhibit mRNA translation or lead to direct degradation of miRNA level, indicating the influence degree of post-transcriptional gene silencing (13). Previous studies have shown that a variety of miRNA molecules are abnormally expressed in osteosarcoma tissues and cells and are closely related to invasion, proliferation, apoptosis and drug resistance of osteosarcoma cells (14). Among them, miR-144 has been used as a molecular diagnostic marker for colon cancer in clinic (15). However, whether miR-144 affects the biological function of osteosarcoma cells remains unknown and the mechanism is still unclear.

Therefore, this study investigated the influence mechanism of miRNA-144 on the proliferation and apoptosis of 
osteosarcoma cells, in order to provide a reference for early diagnosis and targeted therapy of osteosarcoma.

\section{Patients and methods}

Baseline data. A total of 51 cases of osteosarcoma tissue samples were collected in the department of orthopedic surgery, Xuzhou Children's Hospital, Xuzhou Medical University from January 2014 to February 2017. Further 48 cases of normal bone tissue (from tumor lesions $>5 \mathrm{~cm}$ ) samples were collected. In the 51 cases of osteosarcoma, there were 27 males and 24 females. In addition, serum of 51 patients with osteosarcoma and serum of 48 normal persons were collected. The average age was $20.63 \pm 4.63$ years.

Inclusion and exclusion criteria. Inclusion criteria: No radiotherapy, chemotherapy or immunotherapy before surgery; all patients were treated surgically in the above hospital and osteosarcoma and normal bone tissue samples were confirmed by pathology; postoperative tissue samples were marked and saved immediately in liquid nitrogen; clinical data is complete; the study was approved by the hospital ethical committee and and the subjects signed a full informed consent.

Exclusion criteria: Patients with other malignant tumors; patients with liver and kidney function disease; hematological systemic disease; psychical disease; patients with infection before admission; systemic autoimmune diseases.

Culture and transfection of cells. HFOB1.19, MG-63, U2-OS were inoculated into the culture dish. RPMI-1640 medium containing $15 \%$ fetal bovine serum and $1 \%$ penicillin-streptomycin was added to the cell culture incubator at $37^{\circ} \mathrm{C}, 5 \% \mathrm{CO}_{2}$. It was cultured under constant temperature and saturated humidity. Liquid was changed, routine trypsin digestion and passage were conducted. Then cells in logarithmic growth phase were taken for follow-up experiments. The cells were inoculated into a 6 -well plate at a concentration of $1 \times 10^{5}$ cells/well and cultured until the degree of fusion reached $60-70 \%$. The cells were divided into 3 groups. miR-144 mimics (50 pmol/1) and $10 \mu 1$ Lipofectamine 2000 were added to the mimics group. miR-144 inhibitor (50 pmol/l) and $10 \mu \mathrm{l}$ Lipofectamine 2000 were added as the inhibitor group. miR-144 negative control (50 pmol/l) and $10 \mu \mathrm{l}$ Lipofectamine 2000 were added to the NC group (negative control fragment), respectively. Cells were transfected by Lipofectamine $2000 \mathrm{kit}$. The procedure was carried out in strict accordance with the kit instructions. The primers were transfected into cells with the highest differential expression.

\section{Detection method}

qRT-PCR detection. Total RNA was extracted from tissues and cultured cells by using a TRIzol extraction kit (Invitrogen; Thermo Fisher Scientific, Inc.). The concentration and purity of RNA were detected by using a NanoDrop 2000 ultraviolet spectrophotometer. RNA was reverse transcribed into cDNA according to Takara reverse transcription kit (Invitrogen; Thermo Fisher Scientific, Inc.) and the synthesized cDNA was stored at $-20^{\circ} \mathrm{C}$ for later use. Primers: U6 as internal reference, miR-144 upstream, 5'-GCT GGG ATA TCA TCA TAT ACT G-3' and downstream, 5'-CGG ACT AGT ACA TCA TCT
ATA CTG-3'; U6 upstream, 5'-CTC GCT TCG GCA GCA CA-3' and downstream, 5'-AAC GCT TCA CGA ATT TGC GT-3'. The primers were designed and synthesized by Shanghai GenePharma Co., Ltd. The reaction was carried out on an ABI PRISM 7500 fluorescence ration PCR instrument (Applied Biosystems; Thermo Fisher Scientific, Inc.). The PCR amplification cyclic conditions were: Pre-degeneration at $94^{\circ} \mathrm{C}$ for $30 \mathrm{sec}$, degeneration at $94^{\circ} \mathrm{C}$ for $5 \mathrm{sec}$, annealing and extension at $60^{\circ} \mathrm{C}$ for $30 \mathrm{sec}$, for a total of 40 cycles. Each sample was tested 3 times and the relative expression of the gene was expressed by $2^{-\Delta \mathrm{CT}}$ after numeration.

WB detection. Total protein was extracted by RIPA lysis from each group of cells after culture. Protein concentration was detected by BCA. The protein concentration was adjusted to $4 \mu \mathrm{g} / \mu \mathrm{l}$. Then electrophoresis was used with $12 \%$ SDS-PAGE and transferred to PVDF film after ionization, then dyed with ponceau working fluid, soaking and washing in PBST for $5 \mathrm{~min}$, and blocked with 5\% skim milk powder for 2 h. First antibody $(1: 1,000)$ was added and sealed overnight at $4^{\circ} \mathrm{C}$. The first antibody was removed by washing the film, and horseradish peroxidase conjugated goat anti-rabbit second antibody $(1: 5,000)$ was added, incubated at $37^{\circ} \mathrm{C}$ for $1 \mathrm{~h}$, and rinsed 3 times with PBS for 5 min each time. Development was carried out in a darkroom and the excess liquid on the film was dried with filter paper. The ECL was illuminated and developed. The protein bands were scanned and the gray values were analyzed in the Quantity One. Relative expression level of its protein = the gray value of the target protein band/ the gray value of the $\beta$-actin protein band.

Detection of cell proliferation-8 (CCK-8). After $24 \mathrm{~h}$ of transfection, the cells were collected and adjusted to $4 \times 10^{6}$ cells. The cells were diluted into a cell suspension of $5 \times 10^{5}$ cells $/ \mathrm{ml}$ and $100 \mu \mathrm{l}$ of the cells were collected and inoculated into a 96-well plate. After cultured for 24, 48, 72 and $96 \mathrm{~h}, 10 \mu \mathrm{l} \mathrm{CCK}$ solution and $90 \mu \mathrm{l}$ basic medium were added to each well. Detection solution was prepared according to CCK-8 solution: Culture solution, 1:9. $100 \mu \mathrm{l}$ of the test solution was added to each well, incubated for $2 \mathrm{~h}$ and cultured at $37^{\circ} \mathrm{C}$ for $2 \mathrm{~h}$. Then the OD value of each group was measured under the absorbance of $570 \mathrm{~nm}$ by using enzyme-labelling measuring instrument.

Detection of apoptosis by flow cytometry. The cells were removed after transfection for $48 \mathrm{~h}$ and digested by trypsin, and then washed twice with PBS after digestion. Binding buffer $(100 \mu \mathrm{l})$ was added to collocate a suspension of $1 \times 10^{6}$ cells $/ \mathrm{ml}$. Annexin V-FITC and PI were added and incubated at room temperature for $5 \mathrm{~min}$ away from light, and then placed in flow cytometer tube. FACSCanto flow cytometry (Becton-Dickinson) was used to complete the detection within $1 \mathrm{~h}$. The experiment was repeated three times. Annexin V single-staining indicated early apoptosis of cells. Annexin V/PI double staining indicated advanced apoptosis of cells.

Main instruments and reagents. UV-Spectrophotometer (NanoDrop 2000; Beijing Keyi Xingye Technology Development Co., Ltd.), 7500 fluorescence quantitative PCR instrument (ABI), flow cytometry (FACSCanto II; American BD Company), RNA extraction kit (TRIzol and reverse transcription kit (Invitrogen; Thermo Fisher Scientific, Inc.), CCK-8 kit, (C0037; Beyotime Biotechnology), RIPA reagent, BCA protein kit, ECL luminescence kit, trypsin, Lipofectamine 2000 Transfection 
Table I. Relationship between miR-144 in osteosarcoma tissues and clinicopathological features of patients.

\begin{tabular}{|c|c|c|c|c|}
\hline Category & $\mathrm{n}(51)$ & miR-144 & F/t-value & P-value \\
\hline Sex & & & 1.759 & 0.085 \\
\hline Male & 27 & $0.672 \pm 0.194$ & & \\
\hline Female & 24 & $0.763 \pm 0.173$ & & \\
\hline Age (years) & & & 0.889 & 0.378 \\
\hline$\leq 15$ & 26 & $0.815 \pm 0.139$ & & \\
\hline$>15$ & 25 & $0.778 \pm 0.158$ & & \\
\hline Grade of malignancy & & & 1.464 & 0.242 \\
\hline Grade 1 & 13 & $0.724 \pm 0.139$ & & \\
\hline Grade 2 & 20 & $0.703 \pm 0.143$ & & \\
\hline Grade 3 & 18 & $0.636 \pm 0.156$ & & \\
\hline Pathological types & & & 2.270 & 0.093 \\
\hline Osteoblastic type & 12 & $0.633 \pm 0.158$ & & \\
\hline Chondroblastic type & 13 & $0.648 \pm 0.162$ & & \\
\hline Fibroblastic type & 16 & $0.673 \pm 0.160$ & & \\
\hline Mixed type & 10 & $0.795 \pm 0.156$ & & \\
\hline Degree of pathological differentiation & & & 0.931 & 0.401 \\
\hline Well differentiated & 12 & $0.825 \pm 0.196$ & & \\
\hline Moderately differentiated & 25 & $0.767 \pm 0.185$ & & \\
\hline Poorly differentiated & 14 & $0.741 \pm 0.178$ & & \\
\hline
\end{tabular}

Reagent (89901, 23225, 32209, 90059, 11668030; American Thermo Scientific), Bax, caspase-3, Bcl-2 HPR-labeled goat anti-mouse IgG secondary antibody (AF820, AF835, AF810; R\&D Systems, Inc.), Annexin V/PI apoptosis detection kit (40302ES20; Shanghai Yu Sheng Biotechnology Co., Ltd.).

Statistical methods. Statistical analysis was performed by using SPSS 20.0 (Beijing Easybio Technology Co., Ltd.). The data was drawn by using GraphPad Prism 7 (Shenzhen Soft Network Co., Ltd.). Measurement data were expressed as mean number \pm standard deviation (mean \pm SD). Measurement data were compared by using independent sample t-test among groups. Multiple time-point data were compared by repeated measures analysis of variance, expressed as F. At $\mathrm{P}<0.05, \mathrm{ROC}$ was used to plot the diagnostic value of miR-144 in patients with osteosarcoma. Pearson's test analyzed the correlation between miR-144 and serum in the tissue. $\mathrm{P}<0.05$ indicates a statistically significant difference.

\section{Results}

Expression of miR-144 in osteosarcoma tissues and normal bone tissues in osteosarcoma and normal human serum. The relative expression of miR-144 in osteosarcoma tissues and normal bone tissues were $0.763 \pm 0.214$ and $1.546 \pm 0.483$, respectively. The relative expression of miR-144 in osteosarcoma tissues was significantly lower than that in normal bone tissue $(\mathrm{t}=10.530, \mathrm{P}<0.001)$. The relative expression of miR-144 in osteosarcoma and normal human serum were $1.163 \pm 0.514$ and $1.974 \pm 0.612$, respectively. The relative expression of miR-144 in osteosarcoma serum was significantly lower than that in normal human serum $(\mathrm{t}=6.947, \mathrm{P}<0.001)$ (Fig. 1).
Relationship between miR-144 in osteosarcoma tissues and clinicopathological features of patients. There was no significant difference in the expression of miR-144 in osteosarcoma tissues in terms of sex, age, grade of malignancy, pathological types, or degree of pathological differentiation $(\mathrm{P}>0.05)$ (Table I).

Correlation of miR-144 expression between serum and tumor tissues. We analyzed the relationship between serum and cancer tissues and miR-144 expression by Pearson's correlation and found that the serum of patients was positively correlated with the cancer tissue miR-144 expression $(r=0.688$, $\mathrm{P}<0.001$ ) (Fig. 2).

Diagnostic value of miR-144 in patients with osteosarcoma. ROC curve was drawn to analyze the diagnostic value of miR-144 in patients with osteosarcoma through expression of miR-144 in patients with osteosarcoma and normal population. It was found that the area under the miR-144 curve was 0.852, 95\% CI, 0.768-0.936 (Fig. 3 and Table II).

Expression of miR-144 in osteosarcoma cell line. The expression of miR-144 in each group was detected. It was found that the relative expression levels of miR-144 in hFOB1.19, MG-63 and U2-OS were $3.637 \pm 0.534,0.852 \pm 0.274,0.726 \pm 0.242$, respectively. The relative expression of miR-144 in MG-63 and U2-OS cells was significantly lower than that in hFOB1.19 cells $(\mathrm{P}<0.001)$, while the relative expression of miR-144 in U2-OS cells was significantly lower than that in MG-63 cells $(\mathrm{P}<0.05)$. U2-OS cells were transfected with miR-144-mimics. The results showed that the relative expression of miR-144 in U2-OS cells of mimics group was significantly higher than 
Table II. ROC curve data.

\begin{tabular}{|c|c|c|c|c|c|c|}
\hline Index & AUC & $95 \% \mathrm{CI}$ & Specificity & Sensitivity & Youden index & Cut-off \\
\hline VEGF & 0.852 & $0.768-0.936$ & $88.24 \%$ & $73.81 \%$ & $62.05 \%$ & $>1.612$ \\
\hline
\end{tabular}

AUC, area under curve; cut-off, cut-point; ROC, receiver operating characteristics; VEGF, vascular endothelial growth factor.
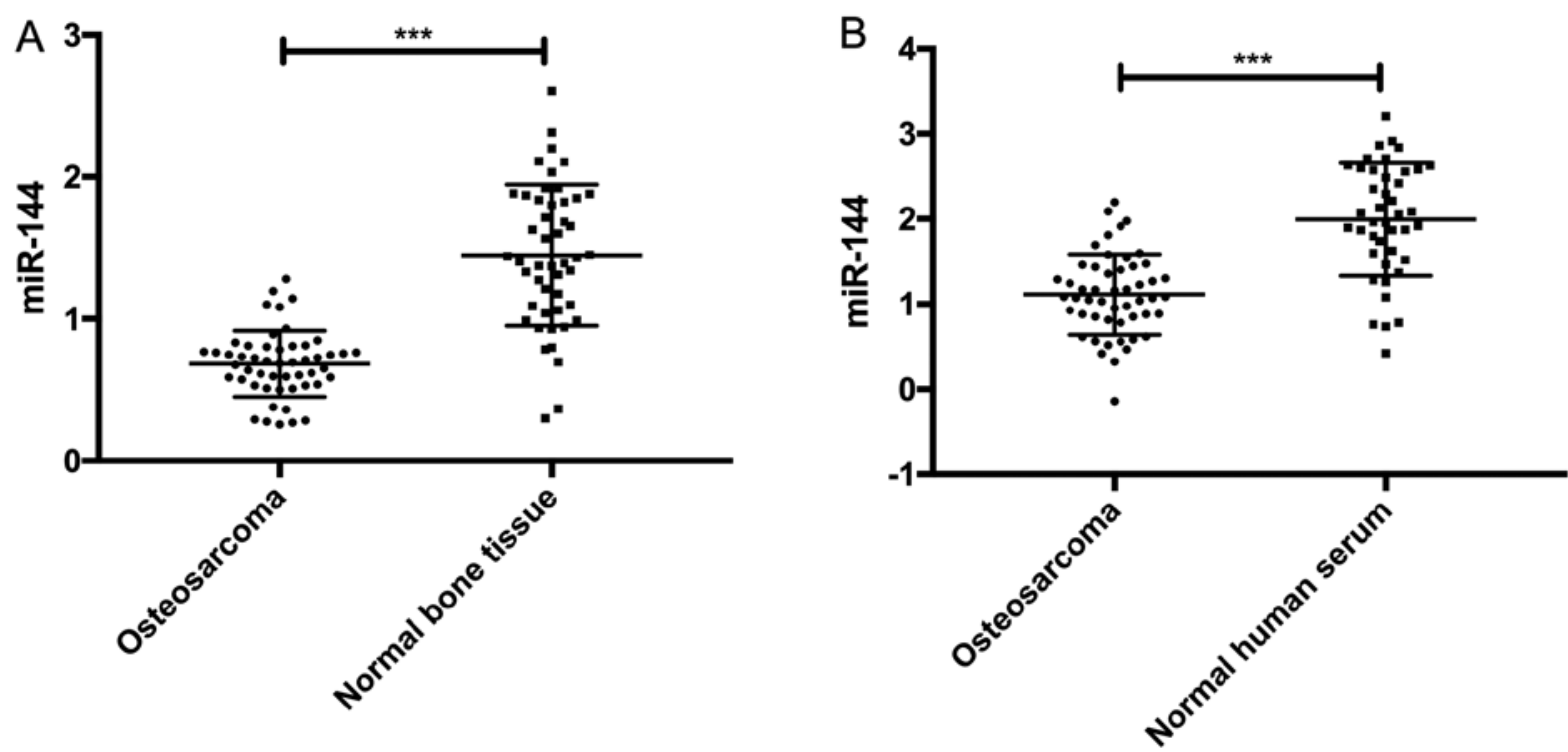

Figure 1. Expression of miR-144 in osteosarcoma tissues and normal bone tissues. (A) Result comparison of the relative expression of miR-144 in osteosarcoma tissues and normal bone tissues. (B) Expression of miR-144 in osteosarcoma and normal human serum. Results of qRT-PCR showed that the relative expression of miR-144 in osteosarcoma tissues was significantly lower than that of normal bone tissue $(\mathrm{t}=10.530, \mathrm{P}<0.001)$. The relative expression of miR-144 in serum of patients with osteosarcoma was significantly lower than that of normal subjects $(\mathrm{t}=6.947, \mathrm{P}<0.001) .{ }^{* * *} \mathrm{P}<0.001$.

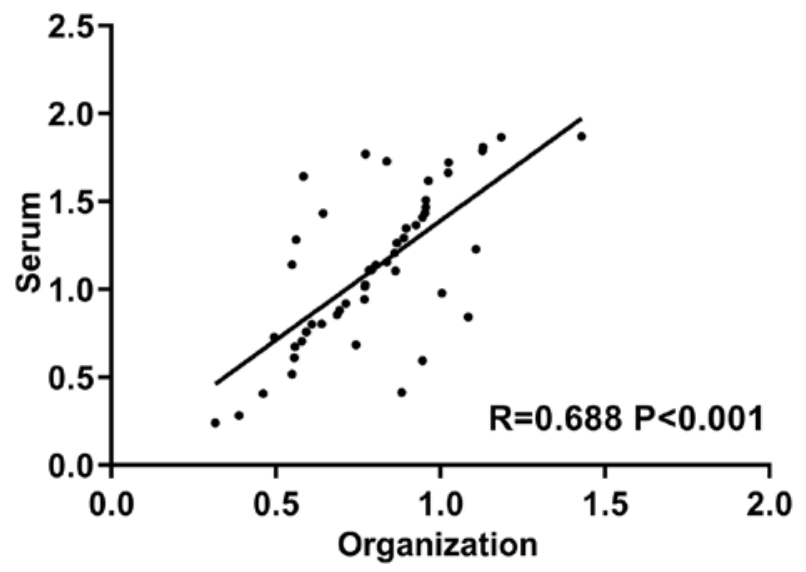

Figure 2. Correlation of serum and tumor tissues with miR-144 expression. Serum of patients was positively correlated with miR-144 expression in cancer tissues $(\mathrm{r}=0.688, \mathrm{P}<0.001)$.

that of inhibitor group and NG group $(\mathrm{P}<0.001)$ and the relative expression of miR-144 in U2-OS cells of inhibitor group was significantly lower than that in mimics group and NG group $(\mathrm{P}<0.001)$ (Fig. 4).

Effect of miR-144 on proliferation and apoptosis of U2-OS cells. The proliferation and apoptosis of cells after transfection

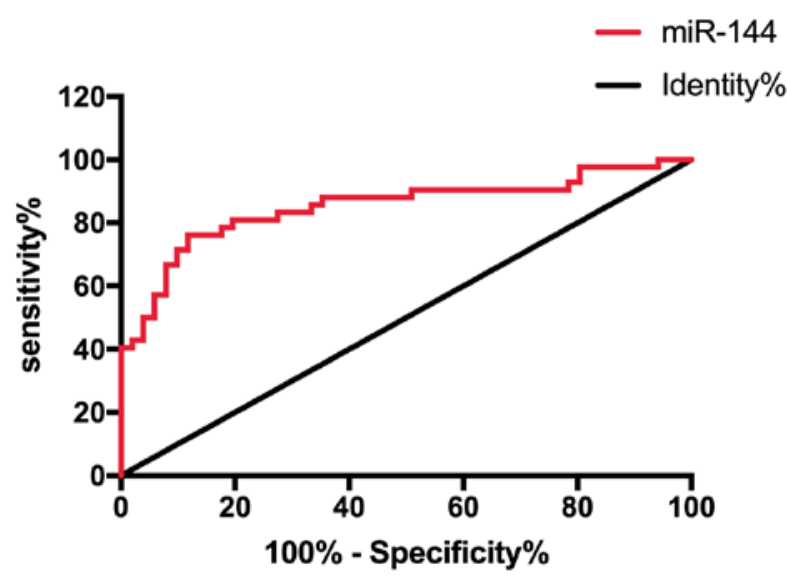

Figure 3. Diagnostic value of miR-144 in patients with osteosarcoma. The area under the miR-144 curve was 0.852 . When the specificity is $88.24 \%$ and the sensitivity is $73.81 \%$, the optimal cut-off point is 1.612 and the youden index is $62.05 \%$.

was detected. The results showed that the proliferation ability of U2-OS cells transfected with miR-144-mimics was significantly inhibited and the apoptosis rate was significantly increased $(\mathrm{P}<0.05)$ (Fig. 5).

Detection of apoptosis protein by WB. WB detection was performed. It was found that the expression of Bcl-2 protein 

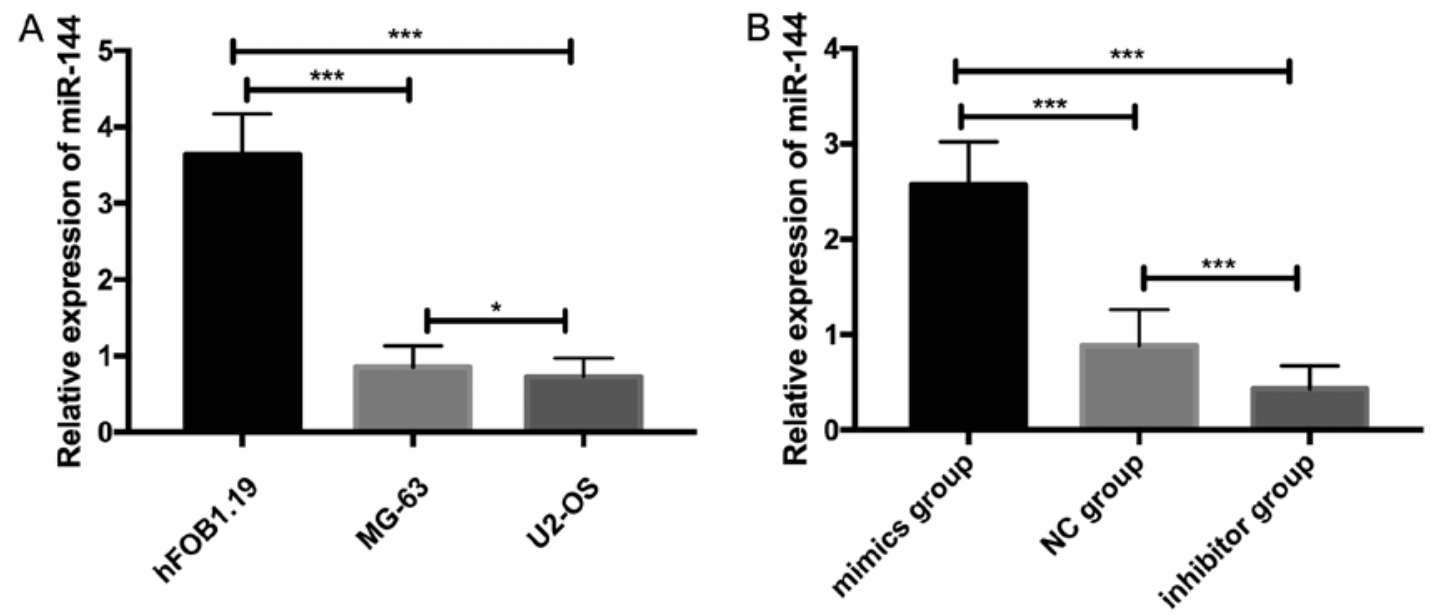

Figure 4. Expression of miR-144 in osteosarcoma cell line. (A) Relative expression level of miR-144 in hFOB 1.19, MG-63, U2-OS. (B) Expression of miR-144 in U2-OS cells after transfection. The expression of hFOB 1.19 is higher that that of MG-63 and U2-OS. ${ }^{* * *} \mathrm{P}<0.001$. The expression of MG-63 is higher that that of U2-OS. ${ }^{*}<0.05$.
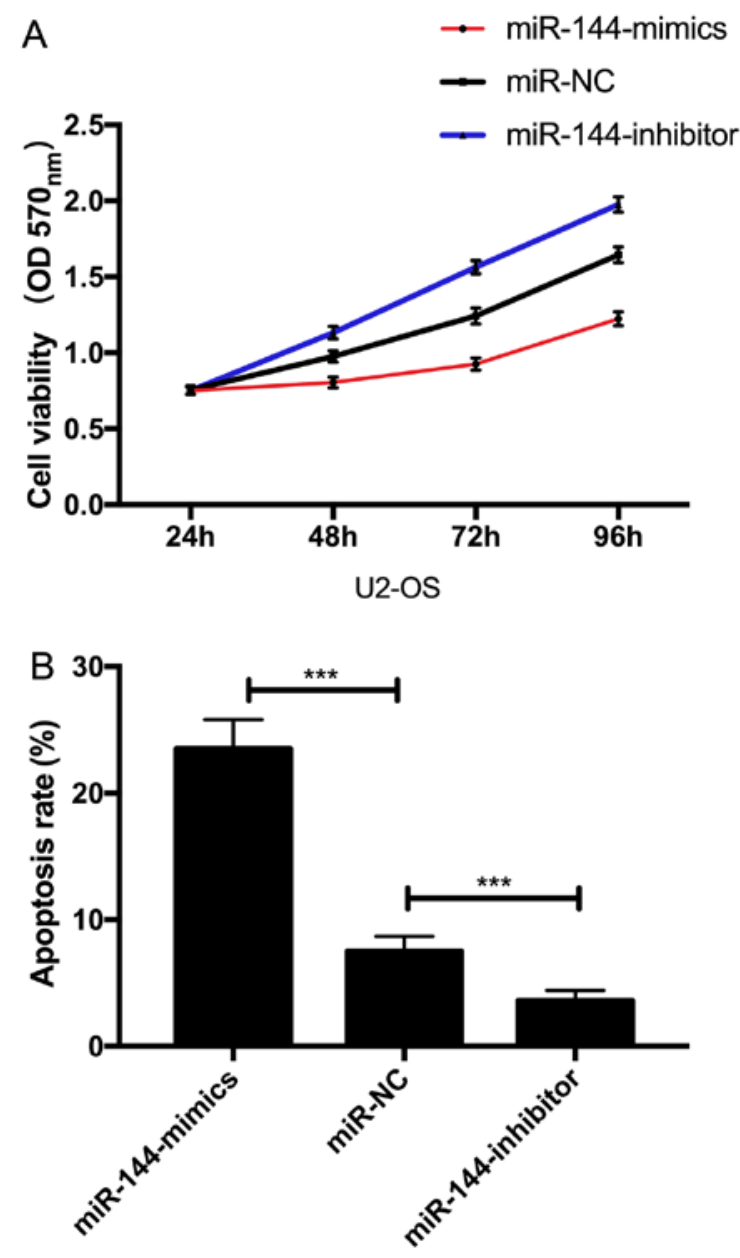

Figure 5. Effect of miR-144 on proliferation and apoptosis of U2-OS cells. (A) Proliferation of U2-OS cells after transfection. (B) Apoptosis of cells after transfection. The apoptosis rate of miR-144-mimics is higher than that of miR-NC and miR-144-inhibitor. ${ }^{* * *} \mathrm{P}<0.05$.

was significantly decreased and the expression of Bax and caspase-3 protein was significantly increased by the expression of Bax, caspase- 3 and Bcl-2 proteins in U2-OS cells transfected with miR-144 (P<0.05) (Fig. 6).
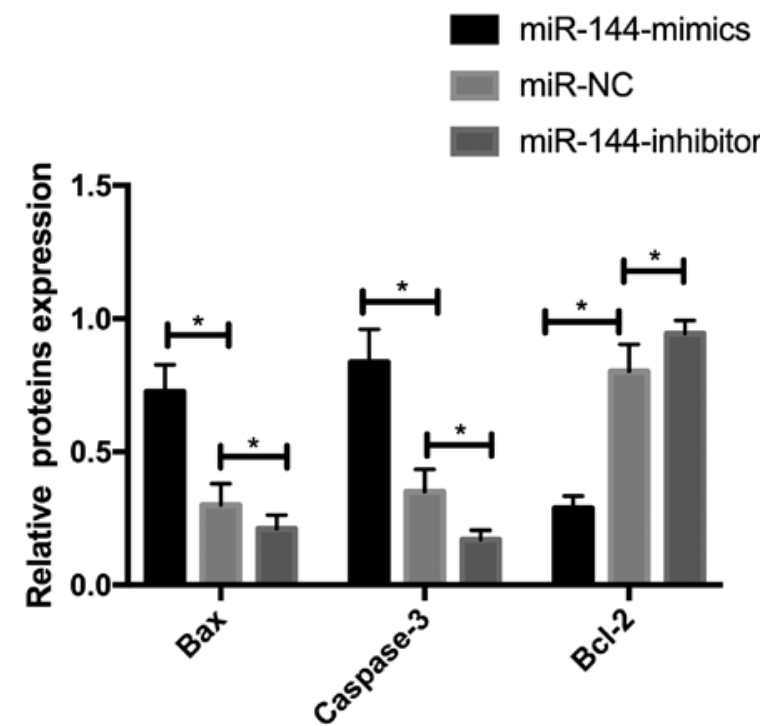

U2-OS

Figure 6. Detection of apoptosis protein by WB. Results show that the pro-apoptotic protein Bax and caspase- 3 are elevated and the antiapoptotic-protein $\mathrm{Bcl}-2$ is decreased. ${ }^{*} \mathrm{P}<0.05$.

\section{Discussion}

Osteosarcoma, the most common of primary malignant bone tumors, originates from formation of mesenchymal cells by normal bone and is characterized by the direct formation of immature bone or osteoid tissue by tumor cells (16). Classic osteosarcoma is a rare, highly malignant tumor with an estimated incidence of 3 cases/million population/year. Osteosarcoma mainly occurs in long bones and rarely occurs in soft tissues. A few years ago, all patients with osteosarcoma were treated with surgery, but the cure rate was $<10 \%$ (17). Almost all patients died within one year after diagnosis and the disability rate and mortality were high (18). With the gradual development of molecular biology, miRNA has become a molecular biology indicator for the treatment strategy and prognosis of osteosarcoma (19). The occurrence 
and deterioration mechanisms of osteosarcoma has not been elucidated, but the proliferation and apoptosis of tumor cells is one of the mechanisms of osteosarcoma (20). Therefore, it is of great significance to explore the molecular biological markers closely related to the occurrence and deterioration of osteosarcoma for the diagnosis and molecular therapy of osteosarcoma.

miR-144 plays an important role in a variety of diseases (21). Studies by Zhao et al (22) showed that downregulation of miR-144 is associated with osteosarcoma cell growth and invasion by regulating TAGLA expression. Studies by Guo et al (23) showed that the downregulation of miR-144 increase the proliferation of bladder cancer cells by targeting EZH2 and regulating Wnt signaling conduction. The results confirmed that the expression levels of miR-144 were downregulated in bladder cancer, which was similar to the results of our study, indicating miR-144 is downregulated in cancer tissues. In this study, the expression of miR-144 in osteosarcoma was significantly lower than that in normal bone tissue and the expression of miR-144 in serum of osteosarcoma patients was also significantly lower than normal level, thus, the expression trend in serum was consistent with that in tissues. Cao et al (24) showed that, miR-144 was significantly reduced in hepatocellular carcinoma tissue and cell lines. Forced overexpression of miR-144 significantly reduced cell proliferation and increased apoptosis of cells, which was similar to our results. It indicated that miR-144 may also play an important role in the occurrence and deterioration of osteosarcoma. Subsequently, we conducted correlation analysis based on the expression of serum of patients and the expression of miR-144 in the cancer tissues, and the results showed that the serum of patients was positively correlated with the expression of miR-144 in the cancer tissues. The ROC curve was drawn to analyze the diagnostic value of miR-144 in patients with osteosarcoma through the expression of miR-144 in patients with osteosarcoma and normal population. It was found that the area under the miR-144 curve was $0.852,95 \%$ CI, 0.768-0.936. This indicated that miR-144 can be used as a diagnostic indicator for patients with osteosarcoma. Then the expression of miR-144 was examined in osteosarcoma cell lines and it was found that the relative expression of miR-144 was the lowest in U2-OS. By further transfection, the relative expression of miR-144 in U2-OS cells of mimics group was significantly higher than that in inhibitor and NG groups. The proliferation ability of U2-OS cells transfected with miR-144-mimics was significantly inhibited and the apoptosis rate was significantly increased. In the study of Wang et al (25), miR-144 was also significantly downregulated in osteosarcoma cell lines and clinical specimens. The decrease of miR-144 expression in osteosarcoma was closely related to disease progression and metastasis. It indicated that miR-144 can be used as a potential target for the treatment of osteosarcoma. Overexpression of miR-144 can inhibit cell proliferation, promote apoptosis of cells and it has been mutually verified with our previous experiments. Finally, WB detection was performed. The detection results showed that the pro-apoptotic protein Bax and caspase- 3 were elevated and the anti-apoptotic protein $\mathrm{Bcl}-2$ was decreased by the expression of Bax, caspase-3 and Bcl-2 proteins in U2-OS cells transfected with miR-144. Therefore, there is a targeted regulation relationship between miR-144 and Bax, and caspase-3 and Bcl-2.
In this study, we preliminarily proved that miR-144 can promote apoptosis by regulating Bax, caspase-3 and Bcl-2 proteins. However, further study is required.

In conclusion, miR-144 may be involved in the occurrence and deterioration of osteosarcoma. In future, it is expected to become a potential indicator for the diagnosis and treatment of osteosarcoma.

\section{Acknowledgements}

Not applicable.

\section{Funding}

No funding was received.

\section{Availability of data and materials}

The datasets used and/or analyzed during the present study are available from the corresponding author on reasonable request.

\section{Authors' contributions}

XZ, ZL and HQ conceived and designed the study, and drafted the manuscript. XZ, WJ, XC, QG and DL collected, analyzed and interpreted the experimental data. ZL revised the manuscript for important intellectual content. All authors read and approved the final manuscript.

\section{Ethics approval and consent to participate}

The study was approved by the Ethics Committee of Xuzhou Children's Hospital, Xuzhou Medical University (Xuzhou, China). Signed informed consents were obtained from the patients and/or the guardians.

\section{Patient consent for publication}

Not applicable.

\section{Competing interests}

The authors declare that they have no competing interests.

\section{References}

1. Ottaviani G and Jaffe N: Epidemiology of osteosarcoma. In: Pediatric and Adolescent Osteosarcoma. Jaffe N, Bruland SO and Bielack S (eds). Springer, Boston, MA, pp3-13, 2010.

2. Anderson ME: Recent advances in osteosarcoma survival. Orthop Clin North Am 47: 283-292, 2016.

3. Isakoff MS, Bielack SS, Meltzer P and Gorlick R: Osteosarcoma: Current treatment methods and successful cooperative approaches. J Clin Oncol 33: 3029, 2015.

4. Lindsey BA, Markel JE and Kleinerman ES: Osteosarcoma overview. Rheumatol Ther 4: 25-43, 2017.

5. Harrison DJ, Geller DS, Gill JD, Lewis VO and Gorlick R: Existing and future treatments for osteosarcoma. Expert Rev Anticancer Ther 18: 39-50, 2018.

6. Duan Z, Gao Y, Shen J, Choy E, Cote G, Harmon D, Bernstein K, Lozano-Calderon S, Mankin H and Hornicek FJ: miR-15b modulates multidrug resistance in human osteosarcoma in vitro and in vivo. Mol Oncol 11: 151-166, 2017. 
7. Sampson VB, Yoo S, Kumar A, Vetter NS and Kolb EA: Potential targets for microRNAs and osteosarcoma. Front Pediatr 3: 69, 2015.

8. Dong Y, Liang G, Yuan B, Yang C, Gao R and Zhou X: MALAT1 promotes the proliferation and metastasis of osteosarcoma cells by activating the PI3K/Akt pathway. Tumour Biol 36: 1477-1486, 2015.

9. Kulda V, Svaton M, Mukensnabl P, Hrda K, Dvorak P, Houdek Z, Houfkova K, Vrzakova R, Babuska V, Pesek M, et al: Predictive relevance of miR-34a, miR-224 and miR-342 in patients with advanced squamous cell carcinoma of the lung undergoing palliative chemotherapy. Oncol Lett 15: 592-599, 2018.

10. Rupaimoole R and Slack FJ: MicroRNA therapeutics: Towards a new era for the management of cancer and other diseases. Nat Rev Drug Discov 16: 203-222, 2017.

11. Peng L, Chen Y, Ma N and Chen X: NARRMDA: Negative-aware and rating-based recommendation algorithm for miRNA-disease association prediction. Mol Biosyst 13: 2650-2659, 2017.

12. Grosswendt $S$ and Rajewsky N: Essentials of miRNA-dependent control of mRNA translation and decay, miRNA targeting principles, and methods for target identification. In: Essentials of Noncoding RNA in Neuroscience: Ontogenetics, Plasticity of the Vertebrate Brain. Academic Press, London, pp19-38, 2017.

13. Chou CH, Chang NW, Shrestha S, Hsu SD, Lin YL, Lee WH, Yang CD, Hong HC, Wei TY, Tu SJ, et al: miRTarBase 2016: Updates to the experimentally validated miRNA-target interactions database. Nucleic Acids Res 44: D239-D247, 2016.

14. Cai X, Liu Y, Yang W, Xia Y, Yang C, Yang S and Liu X: Long noncoding RNA MALAT1 as a potential therapeutic target in osteosarcoma. J Orthop Res 34: 932-941, 2016.

15. Sheng S, Xie L, Wu Y, Ding M, Zhang T and Wang X: miR-144 inhibits growth and metastasis in colon cancer by downregulating SMAD4. Biosci Rep 39: BSR20181895, 2019.

16. Brown HK, Tellez-Gabriel M and Heymann D: Cancer stem cells in osteosarcoma. Cancer Lett 386: 189-195, 2017.
17. Picci P: Osteosarcoma (osteogenic sarcoma). Orphanet J Rare Dis 2: 6, 2007.

18. Rickel K, Fang F and Tao J: Molecular genetics of osteosarcoma. Bone 102: 69-79, 2017.

19. Li Z, Yu X and Shen J: Long non-coding RNAs: Emerging players in osteosarcoma. Tumour Biol 37: 2811-2816, 2016.

20. Liu C and Lin J: Long noncoding RNA ZEB1-AS1 activates ZEB1 as an oncogene of osteosarcoma by epigenetic inheritance. Am J Transl Res 8: 4095, 2016.

21. Chen S, Li P, Li J, Wang Y, Du Y, Chen X, Zang W, Wang H, Chu H, Zhao G, et al: miR-144 inhibits lung cancer cell proliferation and induces apoptosis and autophagy by targeting TIGAR. Cell Physiol Biochem 35: 997-1007, 2015

22. Zhao M, Huang J, Gui K, Xiong M, Cai G, Xu J, Wang K, Liu D, Zhang X and Yin W: The downregulation of miR-144 is associated with the growth and invasion of osteosarcoma cells through the regulation of TAGLN expression. Int J Mol Med 34: 1565-1572, 2014

23. Guo Y, Ying L, Tian Y, Yang P, Zhu Y, Wang Z, Qiu F and Lin J: miR-144 downregulation increases bladder cancer cell proliferation by targeting EZH2 and regulating Wnt signaling. FEBS J 280: 4531-4538, 2013.

24. Cao T, Li H, Hu Y, Ma D and Cai X: miR-144 suppresses the proliferation and metastasis of hepatocellular carcinoma by targeting E2F3. Tumour Biol 35: 10759-10764, 2014.

25. Wang W, Zhou X and Wei M: MicroRNA-144 suppresses osteosarcoma growth and metastasis by targeting ROCK1 and ROCK2. Oncotarget 6: 10297-10308, 2015.

This work is licensed under a Creative Commons Attribution-NonCommercial-NoDerivatives 4.0 International (CC BY-NC-ND 4.0) License. 